\title{
Microarray analysis reveals altered circulating microRNA expression in mice infected with Coxsackievirus B3
}

\author{
CHAOYU SUN ${ }^{1}$, LEI TONG $^{2}$, WENRAN ZHAO $^{3}$, YAN WANG $^{2}$, YUAN MENG $^{2}$, LEXUN LIN $^{2}$, \\ BINGCHEN LIU $^{1}$, YUJIA ZHAI ${ }^{1}$, ZHAOHUA ZHONG $^{2}$ and XUEQI LI ${ }^{1}$ \\ ${ }^{1}$ Department of Cardiology, The Fourth Affiliated Hospital; Departments of ${ }^{2}$ Microbiology and \\ ${ }^{3}$ Cell Biology, Harbin Medical University, Harbin, Heilongjiang 150081, P.R. China
}

Received May 14, 2015; Accepted July 5, 2016

DOI: $10.3892 /$ etm. 2016.3607

\begin{abstract}
Coxsackievirus B3 (CVB3) is a common causative agent in the development of inflammatory cardiomyopathy. However, whether the expression of peripheral blood microRNAs (miRNAs) is altered in this process is unknown. The present study investigated changes to miRNA expression in the peripheral blood of CVB3-infected mice. Utilizing miRNA microarray technology, differential miRNA expression was examined between normal and CVB3-infected mice. The present results suggest that specific miRNAs were differentially expressed in the peripheral blood of mice infected with CVB3, varying with infection duration. Using miRNA microarray analysis, a total of 96 and 89 differentially expressed miRNAs were identified in the peripheral blood of mice infected with CVB3 for 3 and 6 days, respectively. Quantitative polymerase chain reaction was used to validate differentially expressed miRNAs, revealing a consistency of these results with the miRNA microarray analysis results. The biological functions of the differentially expressed miRNAs were then predicted by bioinformatics analysis. The potential biological roles of differentially expressed miRNAs included hypertrophic cardiomyopathy, dilated cardiomyopathy and arrhythmogenic right ventricular cardiomyopathy. These results may provide important insights into the mechanisms responsible for the progression of CVB3 infection.
\end{abstract}

Correspondence to: Professor Xueqi Li, Department of Cardiology, The Fourth Affiliated Hospital, Harbin Medical University, 157 Baojian Road, Harbin, Heilongjiang 150081, P.R. China E-mail: lixueqi@medmail.com.cn

Professor Zhaohua Zhong, Department of Microbiology, Harbin Medical University, 157 Baojian Road, Harbin, Heilongjiang 150081, P.R. China

E-mail: zhongzh@hrbmu.edu.cn

Key words: Coxsackievirus B, circulating microRNAs, microRNA microarray, cardiomyopathy

\section{Introduction}

Coxsackievirus is a type of non-enveloped, linear, positive-sense single-stranded RNA virus that can be divided into group A and B viruses. Group B coxsackieviruses (CVB) include six serotypes (CVB1 -CVB6). Infants, young children and immunocompromised individuals are particularly susceptible to infection, leading to severe morbidity and mortality. CVB primarily infect organs such as the heart, pleura, pancreas and liver causing myocarditis (1), pleurodynia, pericarditis and hepatitis (2-4) . CVB3 infection leads to cardiomyocyte death and induces diseases such as myocarditis and cardiomyopathy (5). Increasing research has focused on understanding the molecular mechanisms involved in CVB3 infection.

MicroRNAs (miRNAs) are small non-coding RNAs that act posttranscriptionally to regulate gene expression (6). miRNAs have critical roles in numerous biological $(6,7)$ and pathological processes (8-11). The presence of circulating miRNAs often correlates with the presence of disease, such as cancer, myocardial infarction and diabetes, and these have been indicated to be practicable, promising and noninvasive biomarkers (12).

Previous studies demonstrated that miRNAs regulate the pathogenesis of viral myocarditis; in the heart tissue of patients with viral myocarditis, several miRNAs have been observed to be differentially expressed (13). miR-155 was indicated as a potential therapeutic target for viral myocarditis as it downregulates cardiac myoblast cytokine expression during CVB3 infection (14). Our previous study also demonstrated that host cellular miRNAs are involved in the regulation of CVB3 biosynthesis by targeting CVB3-coding genes (15). However, little is known about circulating miRNA changes following CVB infection. The present study endeavored to detect miRNA expression changes in the peripheral blood of mice infected with CVB3, with the aim to provide novel insight into the diagnosis and treatment of viral infectious diseases.

\section{Materials and methods}

Animals. A total of $182 \mathrm{BALB} / \mathrm{c}$ mice (3-4 days old; weight, $2 \pm 0.2 \mathrm{~g}$ ) were obtained from the Harbin Medical University Experimental Animal Center, Harbin, Heilongjiang, China. All experimental protocols were approved by the Experimental Animal Ethics Committee of Harbin Medical University 
Harbin, Heilongjiang, China. The use of animals conformed to the Guide for the Care and Use of Laboratory Animals, published by the US National Institutes of Health (16).

Establishment of a CVB3 mouse infection model. CVB3 was expressed within the pMKS-1 plasmid, which contained the full-length cDNA of the CVB3 genomic cDNA (obtained from Dr J. Linsay, Whitton of the Scripps Research Institute, La Jolla, CA, USA). The CVB3 H3 strain was prepared by passage through HeLa cells (American Type Culture Collection, Manassas, VA, USA). HeLa cells were cultured in Dulbecco's Modified Eagle's Medium (DMEM; Invitrogen; Thermo Fisher Scientific, Inc., Waltham, MA, USA) supplemented with $10 \%$ fetal bovine serum (FBS; Biological Industries, Kibbutz Beit Haemek, Israel) and antibiotics $(50 \mathrm{U} / \mathrm{ml}$ penicillin and $0.1 \mathrm{mg} /$ $\mathrm{ml}$ streptomycin) at $37^{\circ} \mathrm{C}$ with $5 \% \mathrm{CO}_{2}$. Two CVB3 variants, EGFP-CVB3 and RLuc-CVB3, were recovered by transfecting HeLa cells with pEGFP-CVB3 and pRLuc-CVB3, respectively. Briefly, HeLa cells were seeded in 12-well culture plates at the density of $1 \times 10^{5}$ cells/well and cultured for $18-24 \mathrm{~h}$. When $60-70 \%$ confluence was reached, the cells were transfected with $0.8 \mu \mathrm{g}$ pEGFP-CVB3 and pRLuc-CVB3, and maintained in DMEM supplemented with 5\% FBS. Cytopathic effects in the transfected cells were observed at $24 \mathrm{~h}$ post-transfection. The recovered viruses were purified and titered by plaque assay. Viral titers were routinely determined by a $50 \%$ tissue culture infectious dose (TCID50) assay of HeLa cell monolayers. The virus samples were diluted in DMEM. Serially diluted virus samples (from $1 \times 10^{-1}$ to $1 \times 10^{-9}$ ) were added to the HeLa cells in 96-well plates and the quadruplicate samples were used at each dilution. The 96-well plates were incubated for 7 days at $37^{\circ} \mathrm{C}$, and the TCID50 values were measured by counting the cytopathic effects of infected HeLa cells. The TCID50 values were calculated using ID-505.0 software, developed at the National Center for Biotechnology Information (Bethesda, MD, USA). Upon reaching adequate viral copy number, BALB/c mice were intraperitoneally administered a dose of $2 \times 10^{6}$ TCID50 of the virus or the same volume of DMEM, in the case of the normal control (NC) group, which was determined to be day 0 of the experiment. Mice were sacrificed by decapitation (17), and the peripheral blood samples in the CVB3 and negative control (NC) groups were collected on days 0,3 and 6 after infection.

Immunohistochemistry. The myocardial tissues were fixed in $10 \%$ neutral-buffered formalin for $48 \mathrm{~h}$ and embedded in paraffin by routine histochemical procedures (18). Hematoxylin and eosin (HE) staining was used to detect histological changes.

miRNA microarray analysis. The miRNA microarray was conducted by KangChen Bio-Tech (Shanghai, China). Total RNA was extracted using TRIzol reagent (Invitrogen; Thermo Fisher Scientific, Inc., Waltham, MA, USA) and miRNA was extracted using an miRNeasy mini kit (Qiagen $\mathrm{GmbH}$, Hilden, Germany), according to the manufacturer's instructions. The quantity of isolated RNA was assessed with a NanoDrop 1000 UV-Vis Spectrophotometer (Nanodrop Technologies; Thermo Fisher Scientific, Inc., Wilmington, DE, USA). Quantified RNA samples $(0.3 \mu \mathrm{l}$ total RNA and $25 \mu \mathrm{l}$ microRNA) were labeled with a miRCURY Hy3/Hy5 Power labeling kit (Exiqon A/S,
Vedbaek, Denmark) and hybridized on an miRCURY LNA Array (Exiqon A/S). Subsequent to washing with water, the microarrays were scanned using a GenePix 4000 microarray scanner (Molecular Devices, LLC, Sunnyvale, CA, USA) and analyzed using Pro 6.0 software (Molecular Devices, LLC). miRNAs with reported intensities $\geq 30$ were retained for further analysis. The raw expression data of miRNAs were normalized by transforming the expression of each gene into having a mean of 0 and a standard deviation (SD) of 1 (19). Following normalization, the mean of replicate values of each miRNA were used for statistical analysis. The presence of differentially expressed miRNAs was determined using volcano plot filtering, with a threshold of $\geq 2.0$-fold change and a P-value $\leq 0.05$. Finally, hierarchical clustering was performed to demonstrate distinguishable miRNA expression profiling among the samples.

Quantiative polymerase chain reaction ( $q P C R)$. The total RNA was extracted from the samples using TRIzol (Invitrogen; Thermo Fisher Scientific, Inc.), and cDNA was generated using a PrimeScript RT reagent kit (Takara Bio, Inc., Otsu, Japan) according to the manufacturer's instructions. Total RNA $(1 \mu \mathrm{g})$ was used as template for RT along with antisense primers and PrimeScript RT Enzyme Mix I (Takara Bio, Inc.). qPCR was performed in triplicate using SYBR Premix Script Ex Taq II (Takara Bio, Inc.) according to the manufacturer's instructions. Briefly, qPCR was performed with $1 \mu \mathrm{l}$ synthesized cDNA, SYBR PrimeScript Ex Taq II (Takara Bio, Inc.), and sense/antisense primers for a final reaction volume of $20 \mu \mathrm{l}$. The sequences of the primers were as follows: miR-216a reverse transcription (RT): CTCAACTGGTGT CGTGGAGTCGG-CAATTCAGTTGAGCACAGT, forward: TAATCTCAGCTGCAACTGTGA, reverse: CAGTGCGTG TCGTGGAGT; miR-710: RT: CTCAACTGGTGTCGTGGA GTC-GGCAATTCAGTTGAGTCAACT, forward: CCAAGT CTTGGGGAGAGTTGAG, reverse: CAGTGCGTGTCGTGG AGT; miR-377: RT: GTCGTATCCAGTGCGTGTCGT-GGA GTCGGCAATTGCACTGGATACGACCAAAAG, forward: GGGGATCACACAAAGGCAA, reverse: CAGTGCGTG TCGTGGAGT; miR-191: RT: CTCAACTGGTGT-CGTGGA GTCGGCAATTCAGTTGAGAGCTGC, forward: CAA CGGAATCCCAAAAGCAGCTG, reverse: CAGTGCGTG TCGTGGAGT; miR-713: RT: GTCGTATCCAGT-CGTGT CGTGGAGTCGGCAATTGCACTGGATACGACGCT

GTG, forward: GGGGTGCACTGAAGGCA, reverse: CAG TGCGTGTCGTGGAGT; U6 snRNA served as an internal control, U6 RT: CGCTTCACGAATTTGCGTGTCAT, forward: GCTTCGGCAGCACATATACTAAAAT, reverse: CGCTTCACGAATTTGCGTGTCAT. Thermocycling was carried out in a LightCycler 2.0 (Roche, Basel, Switzerland) with the following conditions: 40 cycles of $5 \mathrm{sec}$ at $95^{\circ} \mathrm{C}$, $20 \mathrm{sec}$ at $55^{\circ} \mathrm{C}$ and $15 \mathrm{sec}$ at $72^{\circ} \mathrm{C}$. The analytical procedures of dissociation curve was followed by one cycle of $1 \mathrm{sec}$ at $95^{\circ} \mathrm{C}, 20 \mathrm{sec}$ at $65^{\circ} \mathrm{C}$ and $1 \mathrm{sec}$ at $95^{\circ} \mathrm{C}$. The relative RNA expression data were analyzed using the $2^{-\Delta \Delta \mathrm{Ct}}$ method (20).

Target prediction of miRNAs. The predicted targets of the differentially expressed miRNAs were obtained from the TargetScan (www.targetscan.org/mamm_31/), miRBase (www.mirbase.org) (21), and miRanda (www.microrna.org/microrna/home.do) (22) databases. The 
common results obtained from these databases were regarded as reliable target genes.

Functional assignment of differentially expressed miRNAs. To determine the biological functions of the differently expressed miRNAs in this model, gene ontology (GO) and Kyoto Encyclopedia Genes and Genomes (KEGG) enrichment analyses were performed. These were used for predicting the target genes of statistically significantly altered miRNA, and were conducted using the DAVID Bioinformatics Tool v. 6.7 (http://david.abcc.ncifcrf.gov/). This is a commonly used functional annotation tool that can assess overrepresentation of functional categories among a gene set of interest (23).

Statistical analysis. Statistical analyses were performed using SigmaStat 3.1 software (Systat Software, San Jose, CA, USA). The measurement data are presented as the mean \pm SD and determined by Student's $t$-test. For functional analyses, Fisher's exact test, corrected by the false discovery rate method with an adjusted P-value $<0.01$ following Bonferroni correction, was used to determine the probability that each biological function assigned to that data set was due to chance alone. P-values $<0.05$ were considered to represent a statistically significant difference

\section{Results}

Histopathological changes in the CVB3-infected mouse heart. HE staining was used to confirm the histopathological changes in heart tissues. On day 3 after infection, heart tissues from CVB3-infected mice demonstrated mild inflammation. On day 6 , the heart tissues demonstrated severe myocardial inflammation, with myocardial cell swelling, and the myocardial fibers were in a disorganized array (Fig. 1).

Identification of differentially expressed miRNAs. The miRNA expression profile in CVB3-infected mouse blood was compared with that of NC mice using a miRCURY LNA Array. The fold-change was calculated in this comparison in order to determine the extent and direction of differential expression prior and subsequent to infection. A total of 96 differentially expressed miRNAs were identified (33 upregulated and 63 downregulated) on day 3 after infection. A total of 89 differentially expressed miRNAs were identified (37 upregulated and 52 downregulated) on day 6 after infection. The list of top 10 significantly altered miRNAs are reported in Tables I and II. The miRNAs identified as differentially expressed on day 0 were rejected during the target prediction and functional analysis.

Validation of differentially expressed miRNAs in CVB3-infected mouse blood by qPCR. Several miRNAs were detected by qPCR in order to validate the microarray analysis results. These results indicated that miR-216a and miR-710 were upregulated and miR-337 was downregulated on day 3 after infection; on day 6 after infection, miR-216a and miR-713 were reported to be upregulated and miR-191 was downregulated (Fig. 2). The results of the qPCR for the selected miRNAs were consistent with the miRNA microarray analysis results (Fig. 2), indicating that the results of the miRNA microarray are reliable. Amongst these differentially expressed miRNAs, only miR-216a was upregulated on both day 3 and day 6 after infection.

Functional analysis of differentially expressed miRNAs. To analyze the possible mechanisms involved in CVB3 infection, the predicted miRNA target genes were subjected to GO enrichment analysis. The results revealed that these predicted targets were involved in 287 biological processes, including 81 molecular functions and 81 cellular functions $(\mathrm{P}<0.05)$. The top ten biological processes affected by the differentially expressed miRNAs are reported in Fig. 3. The biological interpretation of the target genes of differential miRNAs was further extended using KEGG pathway enrichment analysis. A total of 66 different metabolic pathways were reported, causative of hypertrophic, dilated or arrhythmogenic right ventricular cardiomyopathy (Table III). These results implied possible roles of alterations to circulating miRNAs in the regulation of the biological processes involved in CVB3 infection.

\section{Discussion}

An infection with CVB3 may induce viral myocarditis, dilated cardiomyopathy and heart failure $(1,2,4)$. However, little is known about the mechanisms involved in developing these symptoms. A large number of miRNAs has been discovered in plants, animal, and certain viruses, in which they regulate gene expression at a posttranscriptional level (24-26). In the cardiovascular system, miRNAs are involved in numerous cardiac pathophysiological processes, including heart development, cardiac hypertrophy, myocarditis, cardiomyopathy and heart failure (27-30).

An increasing number of studies have indicated that miRNAs are involved in the duplication and the pathogenesis of CVB3. miR-203 is one of the most upregulated miRNAs in CVB3-infected murine hearts, which enhances CVB3 replication by targeting the zinc finger protein-148 (31). Myocardial miR-21 expression is significantly decreased in cases of CVB3-induced myocarditis, and negatively correlates with disease severity. miR-21 administration efficiently alleviates CVB3-induced myocarditis by repressing PDCD4-mediated apoptosis (32). We previously reported that miR-10a positively modulates gene expression and affects CVB3 replication during cardiac infection (33). However, little is known regarding circulating miRNA changes after CVB3 infection.

The present study demonstrates novel alterations to miRNA expression in the peripheral blood of mice infected with CVB3. Subsequent to infection, mouse heart tissues revealed inflammation, which became more severe over time. An miRNA microarray analysis demonstrated that miRNAs in the peripheral blood were differentially expressed on days 3 and 6 after infection. This differential miR-216a, miR-710, miR-377, miR-191 and miR-713 expression was validated by qPCR.

In the present study, 66 differentially expressed miRNAs were determined. Among these, miR-132-3p, miR-212-3p, miR-335-5p, miR-92a-2-5p and miR-9-5p were predicted to be associated with cardiac pathologies, including dilated cardiomyopathy, hypertrophic cardiomyopathy and arrhythmogenic right ventricular cardiomyopathy. These miRNAs have been confirmed to be differentially expressed 
Table I. Significantly upregulated miRNAs.

\begin{tabular}{|c|c|c|c|c|c|}
\hline \multirow[b]{2}{*}{ miRNAs } & \multicolumn{2}{|c|}{3 day } & \multirow[b]{2}{*}{ miRNAs } & \multicolumn{2}{|c|}{6 day } \\
\hline & Fold change & P-value & & Fold change & P-value \\
\hline miR-101a-5p & 16.72324 & 0.024329 & miR-883b-5p & 8.899323 & 0.002493 \\
\hline let-7a-5p & 14.94596 & 0.030628 & miR-1192 & 3.343596 & 0.043987 \\
\hline miR-219-5p & 13.38862 & 0.047338 & miR-2137 & 2.100476 & 0.017017 \\
\hline miR-1892 & 12.22507 & 0.014818 & miR-1899 & 2.466724 & 0.010656 \\
\hline miR-9-5p & 11.05589 & 0.000185 & miR-9-3p & 2.376287 & 0.009148 \\
\hline $\operatorname{miR}-190 a-5 p$ & 8.958582 & 0.002267 & miR-713 & 3.690579 & 0.042359 \\
\hline $\operatorname{miR}-542-3 p$ & 8.310468 & 0.040532 & $\operatorname{miR}-21 a-3 p$ & 3.852925 & 0.002557 \\
\hline $\operatorname{miR}-24-2-5 p$ & 7.609792 & 0.017971 & $\operatorname{miR}-465 c-5 p$ & 2.588157 & 0.035946 \\
\hline miR-92a-2-5p & 7.551922 & 0.011545 & miR-25-5p & 4.527052 & 0.039037 \\
\hline miR-342-3p & 7.111589 & 0.000863 & miR-147-3p & 2.640046 & 0.043361 \\
\hline
\end{tabular}

Table II. Significantly downregulated miRNAs.

\begin{tabular}{|c|c|c|c|c|c|}
\hline \multirow[b]{2}{*}{ miRNAs } & \multicolumn{2}{|c|}{3 day } & \multirow[b]{2}{*}{ miRNAs } & \multicolumn{2}{|c|}{6 day } \\
\hline & Fold change & P-value & & Fold change & P-value \\
\hline $\operatorname{miR}-1188-3 p$ & 0.048223 & 0.033206 & miR-125b-5 & 0.114178 & 0.047021 \\
\hline $\operatorname{miR}-135 a-5 p$ & 0.078379 & 0.040663 & miR-541-5p & 0.135516 & 0.037748 \\
\hline miR-1190 & 0.091781 & 0.000221 & $\operatorname{miR}-881-3 p$ & 0.142696 & 0.012731 \\
\hline miR-3067-5p & 0.094127 & 0.012448 & $\operatorname{miR}-363-3 p$ & 0.164122 & 0.046749 \\
\hline $\begin{array}{l}\text { miR-1982.1-3p/ } \\
\text { miR-1982.2-3p }\end{array}$ & 0.110368 & 0.006419 & miR-193a-3p & 0.175409 & 0.023604 \\
\hline miR-1968-3p & 0.110595 & 0.007126 & let-7g-3p & 0.177574 & 0.038513 \\
\hline $\operatorname{miR}-18 b-3 p$ & 0.112993 & 0.009556 & $\operatorname{miR}-31-5 p$ & 0.186043 & 0.009361 \\
\hline miR-3109-5p & 0.117507 & 0.025232 & $\operatorname{miR}-3082-5 p$ & 0.199540 & 0.015887 \\
\hline $\operatorname{miR}-5627-3 p$ & 0.124773 & 0.011820 & $\operatorname{miR}-669 d-5 p$ & 0.219337 & 0.005506 \\
\hline $\operatorname{miR}-5046$ & 0.143941 & 0.004508 & miR-709 & 0.245063 & 0.001812 \\
\hline
\end{tabular}

Control

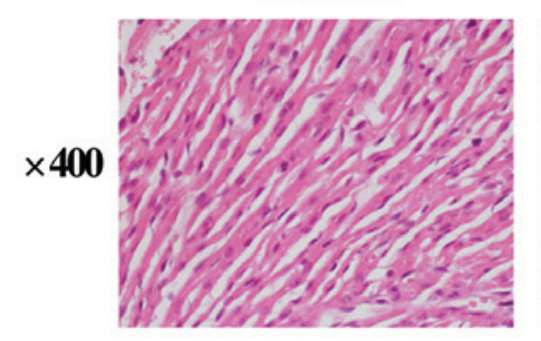

Day 0

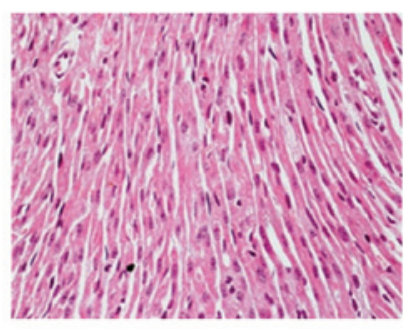

Day 3

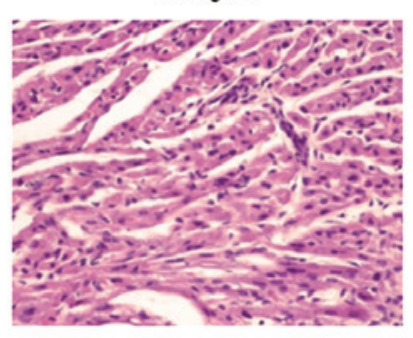

Day 6

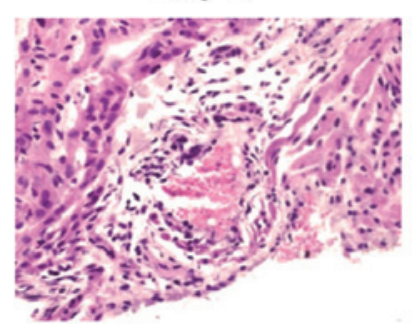

Figure 1. Histopathological changes in the CVB3-infected mouse heart. Hematoxylin and eosin staining was performed on days 0,3 and 6 after infection. On day 3 after infection, heart tissues from CVB3-infected mice demonstrated mild inflammation. On day 6, heart tissues demonstrated severe myocardial inflammation, with myocardial cell swelling, and the myocardial fibers were in a disorganized array. CVB3, Coxsackievirus B3.

and even have an important role in myocardial diseases. It has previously been reported that miR-132, miR-212 and miR-9 were involved in the progression of cardiac hypertrophy (34-37), and circulating levels of miR-92a are significantly reduced in patients with coronary artery disease (38). These previous findings, in conjunction with the current results, indicate that circulating miRNAs may also have a role in the pathogenesis of cardiovascular diseases.

Circulating miRNAs may therefore serve as stable blood-based markers for cancer and cardiovascular 
Table III. Predicted miRNAs involved in CVB3 infection-induced cardiomyopathy.

\begin{tabular}{|c|c|c|c|}
\hline miRNAs & KEGG terms & $\begin{array}{l}\text { Corrected } \\
\text { P-value }\end{array}$ & Hit gene symbols \\
\hline $\operatorname{miR}-132-3 p$ & Dilated cardiomyopathy & 0.044589 & Ryr2, Cacna2d1, Itga9, Gnas, Slc8a1, Actb, Prkacb \\
\hline \multirow[t]{3}{*}{ miR-212-3p } & Dilated cardiomyopathy & 0.022819 & Ryr2, Itgav, Cacna2d1, Itga9, Slc8a1, Actb, Prkacb \\
\hline & Hypertrophic cardiomyopathy & 0.014619 & Itgav, Actb, Prkaa2, Cacna2d1, Ryr2, Slc8a1, Itga9 \\
\hline & $\begin{array}{l}\text { Arrhythmogenic right } \\
\text { ventricular cardiomyopathy }\end{array}$ & 0.055986 & Itgav, Actb, Cacna2d1, Ryr2, Slc8a1, Itga9 \\
\hline \multirow[t]{2}{*}{ miR-335-5p } & Hypertrophic cardiomyopathy & 0.066057 & Itga6, Dag1, Cacng2, Sgcb, Cacna2d1, Ryr2, Slc8a1 \\
\hline & $\begin{array}{l}\text { Arrhythmogenic right } \\
\text { ventricular cardiomyopathy }\end{array}$ & 0.004416 & $\begin{array}{l}\text { Itga6, Dag1, Cacng2, Sgcb, Cacna2d1, Ryr2, Slc8a1, } \\
\text { Gja1 }\end{array}$ \\
\hline \multirow[t]{3}{*}{$\operatorname{miR}-92 a-2-5 p$} & Dilated cardiomyopathy & 0.049858 & Cacna1c, Cacna2d1, Sgcb, Itga5, Atp2a2, Slc8a1, Dmd \\
\hline & Hypertrophic cardiomyopathy & 0.032248 & Sgcb, Atp2a2, Cacna2d1, Cacna1c, Itga5, Slc8a1, Dmd \\
\hline & $\begin{array}{l}\text { Arrhythmogenic right } \\
\text { ventricular cardiomyopathy }\end{array}$ & 0.015516 & Sgcb, Atp2a2, Cacna2d1, Cacna1c, Itga5, Slc8a1, Dmd \\
\hline \multirow[t]{2}{*}{$\operatorname{miR}-9-5 p$} & Dilated cardiomyopathy & 0.083769 & $\begin{array}{l}\text { Dag1, Itga1, Cacna2d1, Adcy5, Slc8a1, Itgb1, Lmna, } \\
\text { Dmd, Itga6, Cacnb4 }\end{array}$ \\
\hline & $\begin{array}{l}\text { Arrhythmogenic right } \\
\text { ventricular cardiomyopathy }\end{array}$ & 0.086685 & $\begin{array}{l}\text { Itga6, Dag1, Cacnb4, Itga1, Cacna2d1, } \\
\text { Itgb1, Slc8a1, Dmd, Lmna }\end{array}$ \\
\hline
\end{tabular}

CVB3, Coxsackievirus B3; KEGG, Kyoto Encyclopedia Genes and Genomes.

A

Day 3

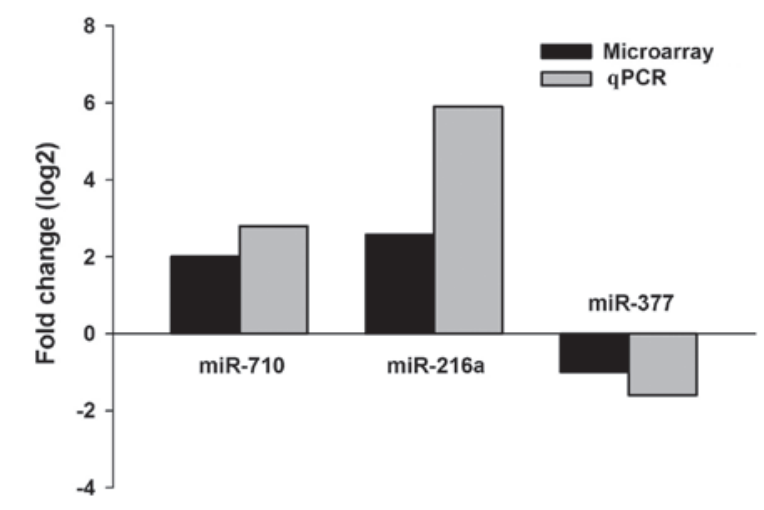

B

Day 6

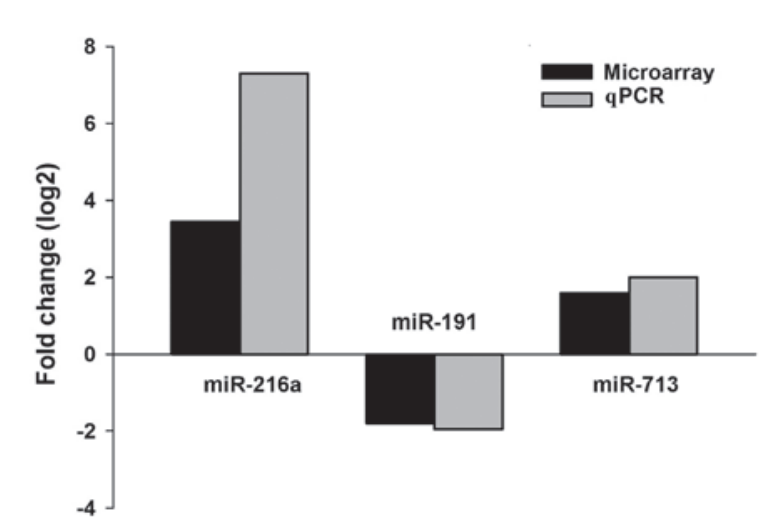

Figure 2. Comparison of microarray data and qPCR results. (A) miR-216a, miR-710 and miR-377 expression levels on day 3 after infection (B). miR-216a, miR-191 and miR-713 expression levels on day 6 after infection. The heights of the columns in the chart represent the log-transformed median fold changes in the expression of CVB3-infected and negative control samples. The microarray data and qPCR results are consistent. qPCR, quantitative polymerase chain reaction; CVB3, Coxsackievirus B3. 


\section{A Biological process}

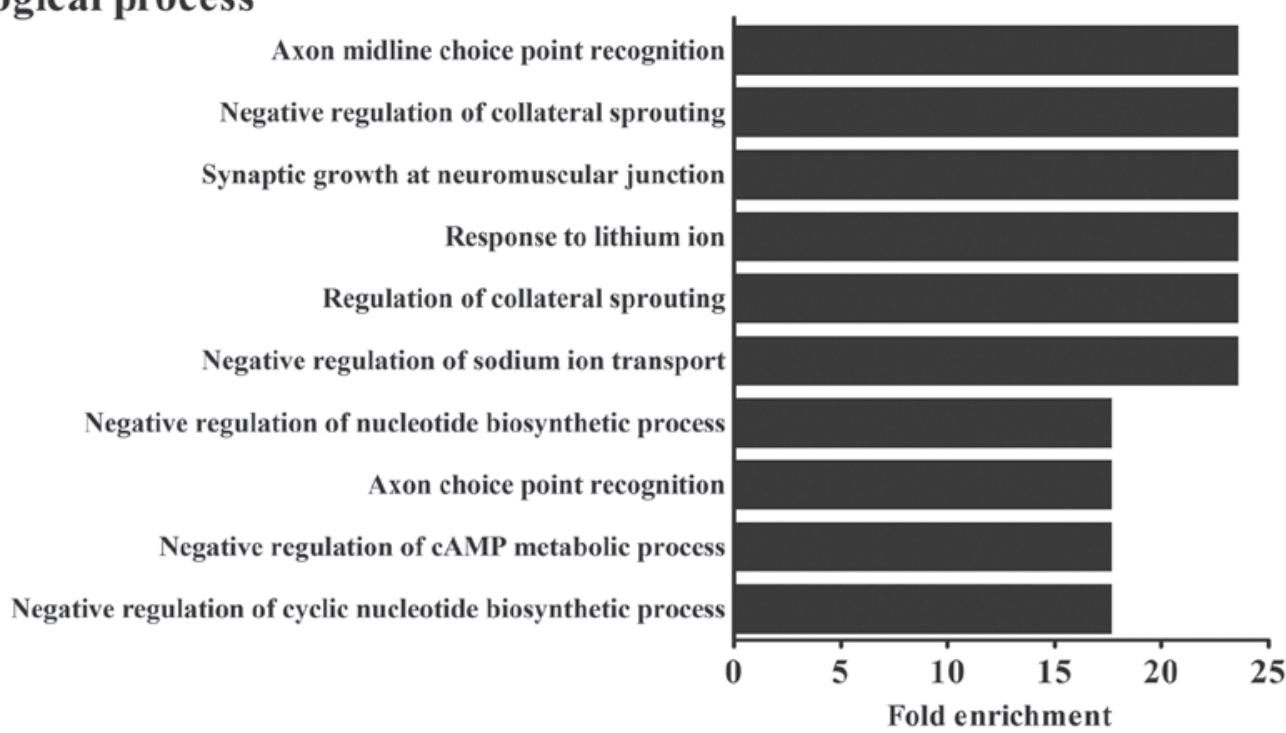

\section{B Cellular component}

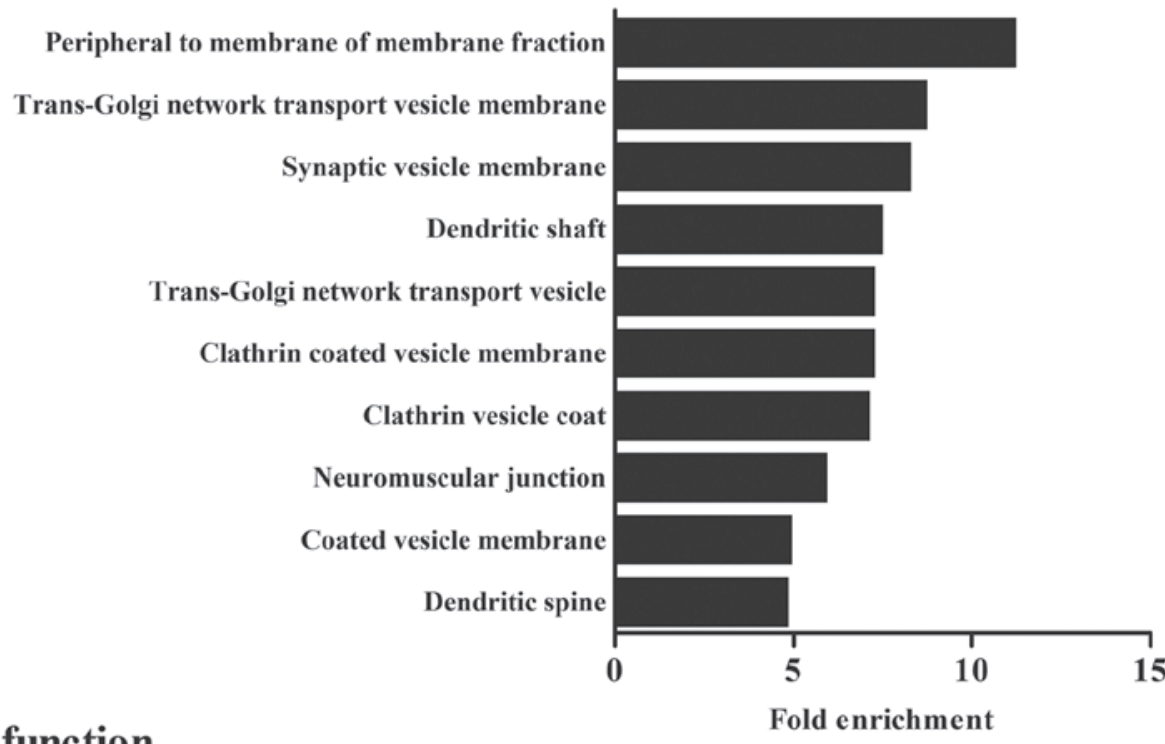

\section{Molecular function}

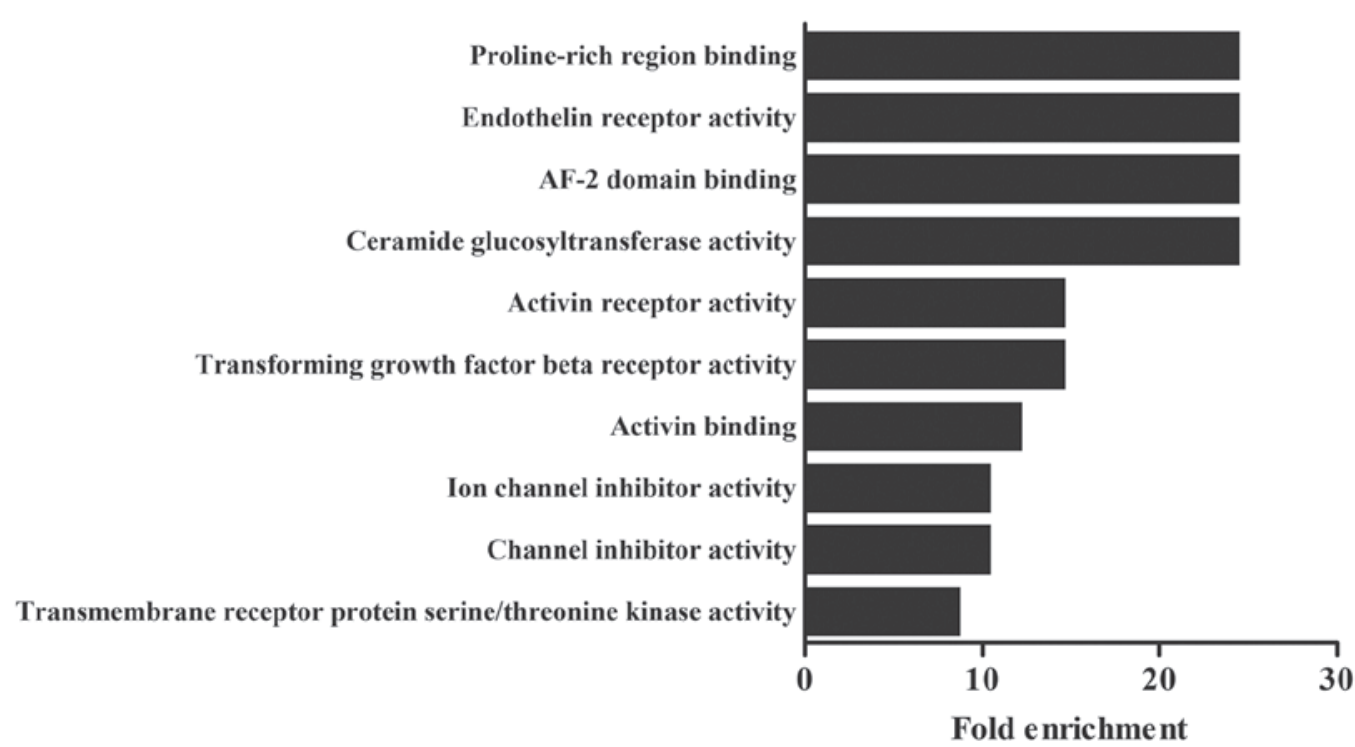

Figure 3. Top 10 enrichment gene ontology terms. (A) Biological process. (B) Cellular components. (C) Molecular functions. The fold enrichment was calculated by the equation: (Count/Population. Hits)/(List. Total/Population. Total). 
diseases (39). However, the biological function of circulating miRNAs is largely unknown. The present findings provide novel evidence for the participation of miRNAs in CVB3 infection. However, the associated mechanisms, including the roles of other organs in the pathogenesis of viral myocarditis, require additional research.

\section{Acknowledgements}

The present study was supported by the Natural Science Foundation of China (grant no. 81271825 to Z. Zhong, grant no. 81101234 to T. Lei), and the Heilongjiang Postdoctoral Grant (grant no. LBH-Z11076 to T.L). The Heilongjiang Provincial Key Laboratory of Pathogens and Immunity, and the Heilongjiang Provincial Science and Technology Innovation Team in Higher Education Institutes for Infection and Immunity, Harbin Medical University, Harbin, China are thanked for their technical help.

\section{References}

1. Knowlton KU: CVB infection and mechanisms of viral cardiomyopathy. Curr Top Microbiol Immunol 323: 315-335, 2008.

2. Kemball CC, Alirezaei $M$ and Whitton JL: Type B coxsackieviruses and their interactions with the innate and adaptive immune systems. Future Microbiol 5: 1329-1347, 2010.

3. Whitton JL: Immunopathology during coxsackievirus infection. Springer Semin Immunopathol 24: 201-213, 2002.

4. Whitton JL, Cornell CT and Feuer R: Host and virus determinants of picornavirus pathogenesis and tropism. Nat Rev Microbiol 3: 765-776, 2005.

5. Yajima T and Knowlton KU: Viral myocarditis: From the perspective of the virus. Circulation 119: 2615-2624, 2009.

6. Bartel DP: MicroRNAs: Genomics, biogenesis, mechanism and function. Cell 116: 281-297, 2004.

7. Karp X and Ambros V: Developmental biology. Encountering microRNAs in cell fate signaling. Science 310: 1288-1289, 2005.

8. Calin GA and Croce CM: MicroRNA signatures in human cancers. Nat Rev Cancer 6: 857-866, 2006.

9. van Rooij E, Sutherland LB, Liu N, Williams AH, McAnally J, Gerard RD, Richardson JA and Olson EN: A signature pattern of stress-responsive microRNAs that can evoke cardiac hypertrophy and heart failure. Proc Natl Acad Sci USA 103 18255-18260, 2006.

10. Bushati N and Cohen SM: MicroRNA functions. Annu Rev Cell Dev Biol 23: 175-205, 2007.

11. Kim J, Inoue K, Ishii J, Vanti WB, Voronov SV, Murchison E, Hannon G and Abeliovich A: A MicroRNA feedback circuit in midbrain dopamine neurons. Science 317: 1220-1224, 2007.

12. De Guire V, Robitaille R, Tétreault N, Guérin R, Ménard C Bambace $\mathrm{N}$ and Sapieha P: Circulating miRNAs as sensitive and specific biomarkers for the diagnosis and monitoring of human diseases: Promises and challenges. Clin Biochem 46 846-860, 2013.

13. Zhang Q, Xiao Z, He F, Zou J, Wu S and Liu Z: MicroRNAs regulate the pathogenesis of CVB3-induced viral myocarditis. Intervirology 56: 104-13, 2013.

14. Bao JL and Lin L: MiR-155 and miR-148a reduce cardiac injury by inhibiting NF- $\kappa \mathrm{B}$ pathway during acute viral myocarditis. Eur Rev Med Pharmacol 18: 2349-2356, 2014.

15. Wang L, Qin Y, Tong L, Wu S, Wang Q, Jiao Q, Guo Z, Lin L, Wang R, Zhao W and Zhong Z: MiR-342-5p suppresses coxsackievirus B3 biosynthesis by targeting the 2C-coding region. Antiviral Res 93: 270-279, 2012.

16. National Research Council (US) Institute for Laboratory Animal Research: Guidance for the description of animal research in scientific publications. National Academies Press, Washington (DC), 2011.

17. Lian HY, Gao Y, Jiao GZ, Sun MJ, Wu XF, Wang TY, Li H and Tan JH: Antioxidant supplementation overcomes the deleterious effects of maternal restraint stress-induced oxidative stress on mouse oocytes. Reproduction 146: 559-568, 2013.
18. Kuhlmann WD. Purification of mouse alpha1-fetoprotein and preparation of specific peroxidase conjugates for its cellular localization. Histochemistry 44: 155-167, 1975.

19. Zhou M, Guo M, He DF, Wang XJ, Cui YQ, Yang HX, Hao DP and Sun J: A potential signature of eight long non-coding RNAs predicts survival in patients with non-small cell lung cancer. J Transl Med 13: 231, 2015.

20. Livak KJ and Schmittgen TD: Analysis of relative gene expression data using real-time quantitative PCR and the 2(-Delta Delta C(T)) Method. Methods 25: 402-408, 2001.

21. Kozomara A and Griffiths-Jones S: MiRBase: Annotating high confidence microRNAs using deep sequencing data. Nucleic Acids Res 42 (Database Issue): D68-D73, 2014.

22. Enright AJ, John B, Gaul U, Tuschl T, Sander C and Marks DS: MicroRNA targets in Drosophila. Genome Biol 5: R1, 2003.

23. Huang da W, Sherman BT and Lempicki RA: Bioinformatics enrichment tools: Paths toward the comprehensive functional analysis of large gene lists. Nucleic Acids Res 37: 1-13, 2009.

24. Ambros V: MicroRNA pathways in flies and worms: Growth, death, fat, stress and timing. Cell 113: 673-676, 2003.

25. Ambros V: The functions of animal microRNAs. Nature 431: 350-355, 2004

26. Barnes D, Kunitomi M, Vignuzzi M, Saksela K and Andino R: Harnessing endogenous miRNAs to control virus tissue tropism as a strategy for developing attenuated virus vaccines. Cell Host Microbe 4: 239-248, 2008.

27. Chen J and Wang DZ: MicroRNAs in cardiovascular development. J Mol Cell Cardiol 52: 949-957, 2012.

28. Huang ZP, Chen J, Seok HY, Zhang Z, Kataoka M, Hu X and Wang DZ: MicroRNA-22 regulates cardiac hypertrophy and remodeling in response to stress. Circ Res 112: 1234-1243, 2013.

29. Bang C, Batkai S, Dangwal S, Gupta SK, Foinquinos A, Holzmann A, Just A, Remke J, Zimmer K, Zeug A et al: Cardiac fibroblast-derived microRNA passenger strand-enriched exosomes mediate cardiomyocyte hypertrophy. J Clin Invest 124: 2136-2146, 2014

30. Thum T, Galuppo P, Wolf C, Fiedler J, Kneitz S, van Laake LW, Doevendans PA, Mummery CL, Borlak J, Haverich A et al: MicroRNAs in the human heart: A clue to fetal gene reprogramming in heart failure. Circulation 116: 258-267, 2007.

31. Hemida MG, Ye X, Zhang HM, Hanson PJ, Liu Z, McManus BM and Yang D: MicroRNA-203 enhances coxsackievirus B3 replication through targeting zinc finger protein-148. Cell Mol Life Sci 70: 277-291, 2013.

32. He J, Yue Y, Dong C and Xiong S: MiR-21 confers resistance against CVB3-induced myocarditis by inhibiting PDCD4-mediated apoptosis. Clin Invest Med 36: E103-E111, 2013.

33. Tong L, Lin L, Wu S, Guo Z, Wang T, Qin Y, Wang R, Zhong X, Wu X, Wang Y et al: MiR-10a* up-regulates coxsackievirus B3 biosynthesis by targeting the 3D-coding sequence. Nucleic Acids Res 41: 3760-3771, 2013.

34. Wang K, Long B, Zhou J and Li PF: MiR-9 and NFATc3 regulate myocardin in cardiac hypertrophy. J Biol Chem 285: 11903-11912, 2010.

35. Katare R, Riu F, Mitchell K, Gubernator M, Campagnolo P, Cui Y, Fortunato O, Avolio E, Cesselli D, Beltrami AP et al: Transplantation of human pericyte progenitor cells improves the repair of infarcted heart through activation of an angiogenic program involving micro-RNA-132. Circ Res 109: 894-906, 2011.

36. Xiao J, Liang D, Zhang Y, Liu Y, Zhang H, Liu Y, Li L, Liang X, Sun Y and Chen YH: MicroRNA expression signature in atrial fibrillation with mitral stenosis. Physiol Genomics 43: 655-664, 2011.

37. Ucar A, Gupta SK, Fiedler J, Erikci E, Kardasinski M, Batkai S, Dangwal S, Kumarswamy R, Bang C, Holzmann A et al: The miRNA-212/132 family regulates both cardiac hypertrophy and cardiomyocyte autophagy. Nat Commun 3: 1078, 2012.

38. Fichtlscherer S, De Rosa S, Fox H, Schwietz T, Fischer A, Liebetrau C, Weber M, Hamm CW, Röxe T, Müller-Ardogan $\mathrm{M}$ et al: Circulating microRNAs in patients with coronary artery disease. Circ Res 107: 677-684, 2010.

39. Wang GK, Zhu JQ, Zhang JT, Li Q, Li Y, He J, Qin YW and Jing Q: Circulating microRNA: A novel potential biomarker for early diagnosis of acute myocardial infarction in humans. Eur Heart J 31: 659-666, 2010. 